\title{
Serum Level Changes of Neurotrophin-3 after Performing Diabetic Foot Exercise in Diabetic Neuropathy
}

\author{
Tri Wahyuliati ${ }^{1}$, Agung Pranoto ${ }^{2}$, Samekto Wibowo ${ }^{3}$ \\ ${ }^{1}$ Department of Neurology, Muhammadiyah University of Yogyakarta, Indonesia \\ ${ }^{2}$ Department of Internal Medicine, Airlangga University, Indonesia \\ ${ }^{3}$ Department of Neurology, Gadjah Mada University, Indonesia
}

\begin{tabular}{l} 
Article Info \\
\hline Article history: \\
Received Aug 15, 2015 \\
Revised Oct 25, 2015 \\
Accepted Nov 28, 2015 \\
\hline
\end{tabular}

Keyword:

Diabetes

Exercise

Foot

Neuropathy

Neurotrophin-3

\begin{abstract}
The research aimed to determine the pattern of changes in serum levels of NT-3 in the improvement of diabetic neuropathy, after doing diabetic foot exercise. A true experimental study with randomaized pre - post test control trial. A total of 36 subjects meeting the inclusion and exclusion criteria were included in the exercise group or the control one with age matched systematic random sampling method. Exercise group had a significant improvement on the score of ABI (p.0.002), systolic blood pressure (p.0.014), diastolic blood pressure (p.0.055), DNS (p.0.01), DNE (p.0.001) and increased of serum level of NT-3 (p.0.049). Control group had result respectively on ABI ( $p .0 .131)$, systolic blood pressure ( $p .0 .668)$, diastolic blood pressure (p.0.216), DNS (p.1.00), DNE (p.0.543), and increase of NT3 (p.0.264). The comparation results of the two groups had a significant different on the score of ABI ( $p .0 .01)$, systolic blood pressure ( $p .0 .01)$, diastolic blood pressure (p.0.01), DNS (p.0.01), DNE ( $p .0 .01$ ), and increased of NT-3 (p.0.01). Diabetic foot exercise had a peripheral affect on a clinically significant improvement based on ABI scores, systolic and diastolic blood pressure, DNS and DNE, and increase of serum level of NT-3.
\end{abstract}

Copyright (C) 2015 Institute of Advanced Engineering and Science. All rights reserved.

\section{Corresponding Author:}

Tri Wahyuliati

Department of Neurology

Universitas Muhammadiyah Yogyakarta, Indonesia

Email: tri.wahyuliati@yahoo.com

\section{INTRODUCTION}

Diabetes mellitus (DM) is one of the major problems for human health in the 21st century. The World Health Organization (WHO) predicts the more increasing number of people with diabetes in various countries including Indonesia [1]-[3].

Since the discovery of insulin, diabetes complications have shifted from acute to chronic complications namely macroangiopathy, microangiopathy and diabetic neuropathy. Diabetic neuropathy is a group of progressive degenerative diseases involving the peripheral nervous system due to DM. Its prevalence ranges from $20 \%$ - 62\% among various countries. In Indonesia, the data and information centers of the Basic Health Research during 2011 informed that diabetic neuropathy affects more than $50 \%$ of diabetic patients with amputation numbers ranging from 15-30\%. In Cipto mangunkusumo Hospital Jakarta (West Java - Indonesia), in 2007, this amputation figures reached 35\% with an increase of 54\% by 2011. In Surabaya (East Java - Indonesia), 51\% patients with diabetes experienced peripheral neuropathy who were found in the outpatient department of polyclinic for diabetes of Dr. Soetomo General Hospital Surabaya. Moreover, in the inpatient department of internal medicine division, it was noted that $90.03 \%$ of neuropathy in diabetes patients was with complications of diabetic foot. These great problems led to a high number of disabilities, declining productivity and huge costs [1]-[3].

Efforts in preventing the disease have been conducted. Indonesian Society of Endocrinology (PERKENI) in 2011 Consensus Management and Prevention of Diabetes Mellitus Type 2 in Indonesia had 
set four main pillars in managing diabetes, namely: education, diet, pharmacology and exercise. DM experts have invented the exercise procedures though not all of the types were recommended for people with diabetes since DM is a chronic disease with various patients' conditions from mild to severe. Those patients with complications need to adjust the intensity. Slower rhythms and movements have been created known as diabetic foot exercise [4].

Various clinical benefits from the exercise for DM patients have been reported as well as those of laboratory, especially the role of growth factor. Nerve growth factor is called neurotrophin, including neurotrophin-3 (NT-3). NT-3 contributes in the prevention of degenerative neurons. NT-3 is unique among neurotrophins in terms of number and potential to stimulate, referring to its ability to activate multiple tyrosine kinase neurotrophin receptor (eg, TrkC and TrkB). All neurotrophins are in muscles, but the majority of afferent muscles (75\%) expresses TrkC and is responsive to NT-3. Muscle contractions in diabetic foot gymnastics will trigger the translocation of GLUT4 so that the transport of glucose into cells increases. This can be employed as energy and reduction of hyperglycemia. Foot exercise also improve blood circulation [5]$[10]$.

Several studies have been performed on the exercise with high and mild intensity associated with neurotrophin, but not the ones with mild stretching exercises like foot exercise related with NT-3, added with the unclear patterns of changes in NT-3 levels. If the pattern can be explained scientifically, the management of diabetes mellitus with diabetic foot gymnastics is accountable [11]-[22].

Accordingly, this study is designed to determine the pattern of changes in serum levels of NT-3 in the improvement of diabetic neuropathy, after doing diabetic foot exercise.

\section{RESEARCH METHOD}

This study is a true experimental one with randomized pre-test post-test control group design method. A total of 36 subjects meeting the inclusion and exclusion criteria were included in the treatment group (18 subjects) or the control one (18 subjects) with age matched systematic random sampling method. Measuring variables was performed before and after the treatment of performing diabetic foot gymnastics for 4 weeks with once-daily dosing. The control group did not perform diabetic foot exercise, but their daily physical activity as usual. Inclusion criteria for this study were: (1) patients with diabetic neuropathy of mild, moderate, or severe level both men and women, (2) aged 40-64 years old, (3) not suffering from a disease affecting the lower extremity and interfering exercise performance, (4) not possessing impaired renal function by examining the levels of uric acid, urea and creatinine, (5) not having mental illness, malignancy, impaired cognition and communication disorders, (6) willing to be a sample by signing informed consent. In addition, exclusion criterion was alcohol consumption.

Foot exercise can improve blood circulation which will be assessed by an ankle brachial index (ABI), systolic and diastolic blood pressure scoring. This blood circulation and energy transport improvement will also improve cell function. This will be a biomolecular assessment through the measurement of serum protein levels potential for improving diabetic neuropathy is NT-3. The patterns of changes in levels of NT-3 will be analyzed. Clinically, improved diabetic neuropathy will be assessed through the signs and symptoms of diabetic neuropathy scale (DNS) and diabetic neuropathy examination (DNE). The other controlled variables are age, sex, HbA1c, BMI, DM and hypertension duration, renal function and lipid profile.

Variables in this research include the independent, dependent and controlled ones. The independent includes diabetic foot exercise, the activity of performing diabetic foot exercise with the procedures as specified by PERKENI, while the dependent ones are ABI scores, systolic and diastolic blood pressure, DNS, DNE, serum levels of NT-3. In addition to the controlled, namely the degree of diabetic neuropathy based on ENMG examination, diabetic patients with status of HbA1c levels, lipid profile of total cholesterol level, HDL, LDL and triglyceride, renal function of uric acid, urea, and creatinine levels, DM and hypertension duration, BMI, age, and sex.

Serum levels of NT-3 were examined with reagents of Human NT-3 Elisa kit of RayBiotech, Inc. products, Norcross, GA 30092, USA, Cat: ELH-NT-3, Lot: 523140 177. Diagnosis of diabetic neuropathy is confirmed with electroneuromyography (ENMG) examination.

The study was conducted in the clinic of internal medicine and neurological of General Hospital at PKU Muhammadiyah, Yogyakarta - Indonesia. The protocol for the research has been approved by the ethics committee of the Faculty of Medicine, Gajah Mada University, and conducted in accordance with the declaration of Helsinki. Data analysis was performed using SPSS 21, the level of significance was set at p $<0.05$. 


\section{RESULTS AND ANALYSIS}

Preliminary data found, the subjects in both groups suffered from no significant differences of mild, moderate and severe neuropathy ( $p 0.370$ ) is shown in Table 1.

Table 1. Basic characteristic - Level of Neuropathy diabetic

\begin{tabular}{ccccccc}
\hline \multirow{2}{*}{$\begin{array}{c}\text { Neuropathy } \\
\text { Diabetic }\end{array}$} & \multicolumn{2}{c}{ Exercise Group } & \multicolumn{2}{c}{ Control Group } & & \\
\cline { 2 - 5 } & $n$ & $\%$ & $n$ & $\%$ & Total & $p^{*}$ \\
\hline Mild & 1 & $5.6 \%$ & 3 & $16.7 \%$ & 4 & \\
Moderate & 6 & $33.3 \%$ & 3 & $16.7 \%$ & 9 & 0.370 \\
Severe & 11 & $61.1 \%$ & 12 & $66.7 \%$ & 23 & \\
Total & 18 & $100 \%$ & 18 & $100 \%$ & 36 & \\
\hline
\end{tabular}

* = Fisher's exact test

There was no significant difference in the examination of renal function in the levels of uric acid ( $p$ $0.619)$ and creatinine ( $p$ 0.652). Urea levels showed a significant difference $(p 0.006)$ but still it is within the range of normal limits (Table 2).

Table 2. Basic Characteristic - Renal function

\begin{tabular}{cccc}
\hline \multirow{2}{*}{ Variable } & Exercise Group & Control Group & \multirow{2}{*}{$p^{*}$} \\
\cline { 2 - 3 } & Mean \pm SD & Mean \pm SD & \\
\hline Uric acid $(\mathrm{mg} / \mathrm{dl})$ & $5.405 \pm 1.235$ & $5.277 \pm 1.059$ & 0.619 \\
Ureum $(\mathrm{mg} / \mathrm{dl})$ & $23.388 \pm 6.308$ & $21.988 \pm 5.882$ & 0.006 \\
Creatinine $(\mathrm{mg} / \mathrm{dl})$ & $0.841 \pm 0.140$ & $0.826 \pm 0.167$ & 0.652 \\
\hline
\end{tabular}

$*=$ Fisher's exact test

Age subjects were matched so that the value of $p=1$. Other characteristics also showed unsignificant difference: gender ( $p$ 0.443), marital status ( $p$ 0.338), education ( $p$ 0.309), occupation ( $p$ 0.194), the type of diabetes therapy ( $p$ 0.084), BMI ( $p$ 0.545). There was a significant different in DM control status in both groups, HbA1c level ( $p$ 0.019) (Table 3).

Table 3. Basic characteristic - categorical data

\begin{tabular}{|c|c|c|c|c|}
\hline Variable & $\begin{array}{c}\text { Exercise Group } \\
n=\end{array}$ & $\begin{array}{c}\text { Control Group } \\
n=\end{array}$ & $\begin{array}{c}\text { Total } \\
n=\end{array}$ & $p^{*}$ \\
\hline Age : $40-48$ yo & 2 & 2 & 4 & \multirow{4}{*}{1.000} \\
\hline $48-56$ yo & 7 & 7 & 14 & \\
\hline $56-64$ yo & 9 & 9 & 18 & \\
\hline Total & 18 & 18 & 36 & \\
\hline Sex : Male & 3 & 6 & 9 & \multirow{3}{*}{0.443} \\
\hline Female & 15 & 12 & 27 & \\
\hline Total & 18 & 18 & 36 & \\
\hline Marital Status : Unmerried & 0 & 1 & 1 & \multirow{4}{*}{0.338} \\
\hline Married & 14 & 16 & 30 & \\
\hline Widow(er) & 4 & 1 & 5 & \\
\hline Total & 18 & 18 & 36 & \\
\hline Education : Elementary & 3 & 1 & 4 & \multirow{4}{*}{0.309} \\
\hline High school & 9 & 6 & 15 & \\
\hline College & 6 & 11 & 17 & \\
\hline Total & 18 & 18 & 36 & \\
\hline Occupation : entrepreneur & 2 & 7 & 9 & \multirow{4}{*}{0.194} \\
\hline employee & 8 & 6 & 14 & \\
\hline ousewife/pension & 8 & 5 & 13 & \\
\hline Total & 18 & 18 & 36 & \\
\hline HbA1c $:$ Good = <6.5\% & 6 & 0 & 6 & \multirow{4}{*}{0.019} \\
\hline Fairly $=6.5-7.0 \%$ & 1 & 1 & 2 & \\
\hline Poorly $=>7.0 \%$ & 11 & 17 & 28 & \\
\hline Total & 18 & 18 & 36 & \\
\hline Therapy : Oral Anti Diabetic & 8 & 10 & 18 & \multirow{4}{*}{0.084} \\
\hline Oral Anti Diabetic + Insulin & 5 & 8 & 13 & \\
\hline No therapy & 5 & 0 & 5 & \\
\hline Total & 18 & 18 & 36 & \\
\hline
\end{tabular}

IJPHS Vol. 4, No. 4, December 2015 : $304-309$ 


\begin{tabular}{|c|c|c|c|c|}
\hline BMI : Normal = 18,5-22,9 & 6 & 10 & 16 & \\
\hline With Risk=23,0-24,9 & 3 & 1 & 4 & \\
\hline Obese I = 25,0-29,9 & 8 & 5 & 13 & 0.545 \\
\hline Obese II > 30 & 1 & 2 & 3 & \\
\hline Total & 18 & 18 & 36 & \\
\hline
\end{tabular}

$$
*=\text { Fisher’s exact test }
$$

The difference was significant in urea and HbA1c levels for both groups. It will be analyzed further by classifying them as co-variant in the statistical analysis.

The other variables of basic characteristic are ABI ( $p$ 0.056), systolic blood pressure ( $p$ 0.772), diastolic blood pressure ( $p$ 0.506), DNS ( $p$ 0.387), DNE ( $p$ 0.761), serum levels of NT-3 ( $p$ 0.676), duration of diabetes mellitus ( $p$ 0.266), duration of hypertension ( $p$ 0.680), cholesterol ( $p$ 0.735), HDL ( $p$ 0.665), LDL ( $p$ 0.479) and triglyceride ( $p 0.725)$, respectively (Table 4$)$.

Table 4. Basic Characteristic - Ratio Data

\begin{tabular}{cccc}
\hline & Exercise Group & Control Group & $n=18$ \\
Variabel & $n=18$ & $p^{*}$ \\
& Mean \pm SD & Mean \pm SD & \\
\cline { 2 - 3 } ABI & $0.919 \pm 0.068$ & $0.886 \pm 0.048$ & 0.056 \\
Systolic (mmHg) & $132.220 \pm 18.568$ & $131.670 \pm 13.827$ & 0.772 \\
Diastolic (mmHg) & $81.110 \pm 8.324$ & $80.830 \pm 5.491$ & 0.506 \\
DNS & $2.110 \pm 1.023$ & $2.170 \pm 0.985$ & 0.387 \\
DNE & $3.220 \pm 2.211$ & $4.280 \pm 2.697$ & 0.761 \\
NT-3 (pg/mL) & $2.850 \pm 0.731$ & $1.199 \pm 0.493$ & 0.676 \\
Duration of DM (yrs) & $7.330 \pm 4.777$ & $8.170 \pm 4.962$ & 0.266 \\
Duration of hypertension (yrs) & $2.500 \pm 0.371$ & $3.610 \pm 0.722$ & 0.680 \\
Cholesterol (mg/dl) & $198.222 \pm 39.478$ & $206.777 \pm 58.567$ & 0.735 \\
HDL (mg/dl) & $51.972 \pm 10.692$ & $46.677 \pm 13.621$ & 0.665 \\
LDL (mg/dl) & $142.444 \pm 29.876$ & $137.333 \pm 52.926$ & 0.479 \\
Triglyceride (mg/dl) & $143.111 \pm 77.398$ & $153.388 \pm 47.241$ & 0.725 \\
\hline * Fisher's exact test & & &
\end{tabular}

At the end of the study, the analysis was conducted on 15 subjects in exercise group, because 3 subjects (16.6\%) dropped out, as one subject experienced an osteoarthritis genu and two other subjects with myalgia (Table 5).

Table 5. Comparation result between two group

\begin{tabular}{|c|c|c|c|c|c|c|c|}
\hline \multirow{3}{*}{ Variable } & \multicolumn{3}{|c|}{ Exercise Group $n=15$} & \multicolumn{3}{|c|}{ Control Group $n=17$} & \multirow{3}{*}{$\begin{array}{c}p^{* * *} \\
\text { (C) }\end{array}$} \\
\hline & Begin & End & $p^{* *}$ & Begin & End & $p^{* *}$ & \\
\hline & Mean $\pm \mathrm{SD}$ & Mean $+\mathrm{SD}$ & (A) & $M e a n+\mathrm{SD}$ & Mean $\pm \mathrm{SD}$ & (B) & \\
\hline $\mathrm{ABI}$ & $0.92 \pm 0.06$ & $1.01 \pm 0.08$ & 0.002 & $0.88 \pm 0.04$ & $0.88 \pm 0.05$ & 0.131 & 0.01 \\
\hline Systolic & $132.00 \pm 20.33$ & $124.00 \pm 14.04$ & 0.014 & $131.76 \pm 14.24$ & $132.35 \pm 11.47$ & 0.668 & 0.01 \\
\hline Diastolic & $82.00 \pm 8.61$ & $78.67 \pm 9.90$ & 0.055 & $80.88 \pm 5.65$ & $82.06 \pm 5.32$ & 0.216 & 0.01 \\
\hline DNS & $2.13 \pm 1.06$ & $1.07 \pm 0.96$ & 0.001 & $2.18 \pm 1.01$ & $2.18 \pm 1.01$ & 1.000 & 0.01 \\
\hline DNE & $3.20 \pm 2.14$ & $1.73 \pm 1.66$ & 0.001 & $4.41 \pm 2.71$ & $4.53 \pm 3.01$ & 0.543 & 0.01 \\
\hline NT-3 & $1.05 \pm 0.23$ & $1.26 \pm 0.38$ & 0.049 & $1.19 \pm 0.50$ & $1.98+1.81$ & 0.264 & 0.01 \\
\hline$* *$ & Paired t test & & & & & & \\
\hline$* * *$ & eneral line & odel & & & & & \\
\hline
\end{tabular}

The study found a significant increase in the exercise group, ABI scores were compared to the control group, from $(0.92 \pm 0.06)$ into $(1.01 \pm 0.08) p 0.002$ vs. $(0.88 \pm 0.04)$ into $(0.88 \pm 0.05) p 0.131$, respectively. This means there were significant differences found in the two groups with the value of $p 0.01$. It occurred in response to muscle contraction of endothelium-dependent vasodilatation or acetylcholine. Muscle contraction in foot gymnastics triggered neurotransmitter of acetylcholine together with the M3 muscarinic receptor that also triggered endothelial derived vasodilator prostanoid, and then diffused into muscles causing vasorelaxation and a decrease in peripheral resistance [12],[13],[18].

Systolic blood pressure in exercise group decreased significantly, from $(132.00+20.33)$ into $(124.00+14.04)$ p 0.014 vs $(131.76+14.24)$ into $(132.35+11.47)$ p 0.668 , respectively. Therefore, the two groups had significant differences with $\mathrm{p}$ value of 0.01 . Diastolic blood pressure also decreased though not significant in exercise group at $(82.00+8.61)$ into $(78.67+9.90)$ p 0.055 , whereas the control group was 
observed with no significant increase from $(80.88+5.65)$ into $(82.06+5.32)$ p 0.216 . Results in each of these groups were not significant, yet they were significant (p 0.01) when compared between the two groups due to the p-value of 0.055 for the exercise group. Hence, this was closer to the significance if the degree of significance was $\mathrm{p}<0.05$, while in the control group, $\mathrm{p}$-value was farther of $\mathrm{p} 0.216$. Improvements in blood pressure occurred with regard to the onset of vasorelaxation and a decrease in peripheral resistance. Overall, this affected blood circulation and pressure improvements [12],[13],[18].

For DNS scores, the results revealed a significant improvement in exercise group, from $(2.13+$ 1.06) into $(1.07+0.96)$ p 0.01 and in the control group from $(2.18+1.01)$ into $(2.18+1.01) \mathrm{p} 1.00$, respectively. Both groups showed significant different results with p 0.01. A significant improvement of DNE values also occurred in the exercise group with a decline, from $(3.20+2.14)$ into $(1.73+1.66) \mathrm{p} 0.001$, in the control group from $(4.41+2.71)$ into $(4.53+3.01)$ p 0.543 , consecutively. Both groups revealed significant different results with p 0.01 . Such improvements were due to muscle contraction in diabetic foot gymnastics causing increased calcium ions, then activated the adenylate cyclase enzyme, hence, the ATP was changed into cAMP. Furthermore, cAMP helped the metabolism process and absorption of extracellular glucose by intra GLUT4 vesicles translocation to move near the membrane surface to transport the extracellular glucose to the cell to be used as energy and to reduce hyperglycemia. Increased cAMP activated cAMP response element-binding protein (CREB) assisting merging damaged fragments of axons and myelin of diabetic neuropathy. Improved blood circulation improved the supply of materials needed for regenerating and repairing axons and myelin. Such mechanism would repair perceptible cell function with improvement of DNS and DNE [23]-[25].

The NT-3 level was examined and discovered a significant improvement at its level, namely, in exercise group from $(1.05+0.23)$ into $(1.26+0.38) \mathrm{p} 0.049$, whereas in the control group from $(1.19+0.50)$ into $(1.98+1.81)$ p 0264 , respectively. Differences were significant with a p-value of 0.01 . These results are in accordance with previous data, claiming that the majority (75\%) of afferent muscle expresses TrkC and is responsive to NT - 3. Foot exercise are more a local work in peripheral through manipulating lower limb muscles, thus, more local impact generates. Neurotrophin levels repair through foot exercise, relying on local factors, can be made possible by the mechanism of the available literature. The data show, that the glucose transporter (GLUT), especially GLUT-4 is the major insulin-responsive glucose transporter, located especially in cell muscle and adipose. In the absence of insulin, about 90 percent GLUT-4 is intracellularly located. Contraction of muscles in the foot exercise can stimulate GLUT-4 translocation to the plasma membrane and enhance glucose transport in skeletal muscle through different pathways from insulin (insulin independent). It allows a person with diabetes to enter muscles with energy by local stimulation i.e. leg muscle contraction in foot exercise. In order to build neurotrophin proteins in regenerative function the energy available is employed [23]-[29].

\section{CONCLUSION}

Thus, it can be concluded that in patients with diabetic neuropathy, diabetic foot exercise has a peripheral effect on a clinically significant improvement based on ABI scores, systolic and diastolic blood pressure, DNS and DNE. A significant increase in serum levels of NT-3.

Accordingly, the study suggests (1) clinicians to include appropriate physical exercise suitable for the patients' condition. Low impact workout such as diabetic foot exercise can still be applied, especially in patients with severe conditions. (2) nurses, gymnastics groups, health counselors, and various stakeholders in health care systems to always manage to implement physical exercise including diabetic foot gymnastics in any effort to improve health status. (3) patients and societies to perform actively even the low impact exercise like diabetic foot gymnastics as proven to provide benefits. (4) further research to be done with varied dose and duration for the observation, subjects selection with homogeneous HbA1c, observation on constrains or triggering adherence factors to workout regularly, (5) therapeutic strategies in the future to consider neurotrophic factors particularly NT-3 level given as the least affected by diabetic foot exercise, for instance, an intra-muscular injection for synthetic NT-3 or an ointment.

This study findings has several limitations: (1) no assessment on neurotrophin levels of skeletal muscles in the feet, (2) no biopsy as a definitive diagnosis of the onset of degeneration and regeneration, (3) the subjects of the study have inequivalent HbA1c levels between two groups, (4) subjects of this research were not grouped according to the basic status of severity in diabetic neuropathy.

\section{REFERENCES}

[1] Anonim, “Indonesian data and information centers”, 2011. pdpersi.co.id.

[2] Anonim, "the Basic Health Research - Indonesian republic health department”, 2007. 
[3] Anonim, "Limb Loss Task Force/Amputee Coalition, Roadmap for Preventing Limb Loss in America: Recommendations From the 2012 Limb Loss Task Force”, Knoxville, Tennessee, 2012.

[4] Perkumpulan Endokrinologi Indonesia (PERKENI), "Konsensus Pengelolaan Dan Pencegahan Diabetes Melitus Tipe 2 Di Indonesia”, 2011.

[5] Anonim, "Neurotrophins”, Encyclopedia of the Neurological Sciences Elsevier Science (USA), 2003.

[6] Anonim, "Neurotrophins", The Free Encyclopedia From Wikipedia, 2012.

[7] Blesch A., "Neurotrophic factor in neurodegeneration”, Brain Pathol., vol. 16, pp. 295-303, 2006.

[8] Blesch A., Tuszynski MH., "Neurotrophic Factor Therapy: NGF, BDNF and NT-3", Encyclopedia of Neuroscience, pp. 1093-1100, 2009.

[9] Anand P., Terenghi G., Warner G., Kopelman P., Williams-Chestnut RE., Sinicropi DV., "The role of endogenous nerve growth factor in human diabetic neuropathy", Nature Medicine, vol. 2, pp. 703 - 707, 1996.

[10] Conner JM., Tuszynski MH., "Neurotrophins: Physiology and Pharmacology”, Encyclopedia of Neuroscience, pp. 1101-1106, 2009.

[11] Andrzej Loesch, Tim Cowen, "On the presence of neurotrophin p75 receptor on rat sympathetic cerebrovascular nerves”, Molecular Histology, vol. 39, pp. 57-68, 2008.

[12] Ballaz L., Fusco N., CrÃ@tual A., Langella B., Brissot R., "Acute peripheral blood flow response induced by passive leg cycle exercise in people with spinal cord injury", Physical Medicine and Rehabilitation, vol/issue: 88(4), pp. 471- 476, 2007.

[13] Biankin SA., Jenkins AB., Campbell LV., Choi KL., Forrest QG., Chisholm DJ., "Target-Seeking Behavior of Plasma Glucose With Exercise in Type 1 Diabetes”, Diabetes Care, vol. 26, pp. 297-301, 2003.

[14] Colberg SR., Albright AL., Blissmer BJ., Braun B., Taber LC., Fernhall B., Regensteiner JG., Rubin RR., Sigal RJ., "Guideline Summary: Exercise and type 2 diabetes: American College of Sports Medicine and the American Diabetes Association”, Med Sci Sports Exerc Diabetes Care, vol. 33, pp. 2282-2303, 2010.

[15] Escorihuela M., Pallàs S., Bayod J., del Valle AM., Canudas JF., Lalanza S., Sanchez-Roige, Camins RM., "Molecular changes in rat brain Long-term treadmill exercise induces neuroprotective”, J Appl Physiol, vol. 111, pp. 1380-1390, 2011.

[16] Eng-Tat Ang, Yee-Kit Tai, Shun-Qiang Lo, Raymond Seet, Tuck-Wah Soong, "Neurodegenerative diseases: exercising toward neurogenesis and regeneration”, Frontiers in Aging Neuroscience, vol/issue: 2(2), 2010. www.frontiersin.org.

[17] Holten MK., Morten Z., Michael G., Carsten J., Jørgen FP., Wojtaszewski, Flemming D., “Strength Training Increases Insulin-Mediated Glucose Uptake, GLUT4 Content, and Insulin Signaling in Skeletal Muscle in Patients With Type 2 Diabetes”, Diabetes, vol. 53, pp. 294-305, 2004.

[18] Huebschmann AG., Kohrt WM., Regensteiner JG., "Exercise attenuates the premature cardiovascular aging effects of DM type 2”, Vasc. Med., vol. 16, pp. 378-390, 2011.

[19] Ritzline PD., Levin AZ., "Foot and ankle exercises in patients with diabetes”, @ 2011 Copyright Lower Extremity Review Magazine, 2011.

[20] Stephan FE., Praet Æ., Luc JC., van Loon, “Exercise therapy in Type 2 diabetes”, Acta Diabetol, vol. 46, pp. 263278, 2009.

[21] Vega SR., Knicker A., Hollmann W., Bloch W., Strüder HK., "Effect of resistance exercise on serum levels of growth factors in humans”, Horm Metab Res., vol/issue: 42(13), pp. 982-6, 2010. doi: 10.1055/s-0030-1267950.

[22] Ying Z., Roy RR., Edgerton VR., Gómez-Pinilla F., "Exercise restores levels of neurotrophins and synaptic plasticity following spinal cord injury”, Exp Neurol., vol/issue: 193(2), pp. 411-9, 2005.

[23] Anonim, “AMP-activated protein kinase”, Free Encyclopedia From Wikipedia, 2012.

[24] Shepherd PR., Kahn BB., "Glucose Transporters and Insulin Action: Implications for Insulin Resistance Diabetes Mellitus”, NEJM, vol. 341, pp. 248-257, 1999.

[25] Tomlinson DR., Natalie JG., “Glucose neurotoxicity”, Nature Publishing Group, vol. 9, 2008. www.nature.com/reviews/neuro.

[26] Gordon T., “The role of neurotrophic factors in nerve regeneration”, Focus, vol/issue: 26(2), 2009. doi: 10.3171/FOC.26.2.E3.

[27] Jungberg CL., Novikov L., Kellerth JO., Ebendal T., Wiberg M., "The neurotrophins NGF and NT-3 reduce sensory neuronal loss in adult rat after peripheral nerve lesion”, Neuroscience Letters, vol. 262, pp. 29-32, 1999.

[28] O’G Vidaurre, Gasco S., Deogracias R., Sobrado M., Cuadrado E., Montaner J., Rodrı A., Díaz-Guerra, "Imbalance of neurotrophin receptor isoforms TrkB-FL/TrkB-T1 induces neuronal death in excitotoxicity", Cell Death and Disease, 2012. doi:10.1038/cddis.2011.143; Subject Category: Neuroscience.

[29] Sayers NM., Beswick LJ., Middlemas A., Calcutt NA., Mizisin AP., Tomlinson DR., Fernyhough P., "Neurotrophin-3 Prevents the Proximal Accumulation of Neurofilament Proteins in Sensory Neurons of Streptozocin-Induced Diabetic Rats”, Diabetes, vol. 52, pp. 2372-2380, 2003. 